\title{
La otra lectura. Una contribución al problema de la lectura en Bi- bliotecología
}

\author{
Héctor Guillermo Alfaro López *
}

Artículo recibido:

26 de octubre de 2004.

Artículo aceptado:

8 de agosto de 2005.

\section{RESUMEN}

Esta contribución al problema de la lectura busca primero mostrar que la Bibliotecología es una disciplina de convergencia disciplinar, y que por eso en ella convergen las perspectivas con que otras disciplinas han tratado el tema de la lectura, esto se ilustra en particular con la Psicología. En la siguiente instancia se explica como la concepción básica de la Bibliotecología contemporánea, respecto al lector y la lectura, requiere ampliarse y completarse con los aportes de otras disciplinas para readquirir su fundamento humanístico. Y de esto finalmente se deriva hacia una comprensión de la dimensión lúdica que entraña la lectura.

* Centro Universitario de Investigaciones Bibliotecológicas de la UNAM, México. galfaro@cuib.unam.mx

INVESTIGACIÓN BiBLIOTECOLÓGICA, Vol. 21, Núm. 43, julio/diciembre, 2007, México, ISSN: 0187-358X. pp. 15-45 
Palabras Clave: Lector; Lectura; Bibliotecología;

Psicología; Humanismo; Liberación.

\section{ABSTRACT}

Another reading. A contribution to the reading problem in library science

Héctor Guillermo Alfaro López

This focus on the reading problem intends to show Library Science as a discipline where other disciplines whose perspectives have also handled the lecture subject converge, like psychology. This instance explains why the basic contemporary library science's conception of reader and reading needs to be widened and completed with the contributions of other disciplines in order to regain its humanistic foundation. It all finally derives from a comprehension of the ludic dimension involved in reading.

Keywords: Reader; Reading; Library Science; Psychology; Humanism; Liberation.

Para Guillermo Ordorica Robles, como simbolo de amistad y agradecimiento.

E 1 lector, desde el momento que abre un libro, dirige su atención, sea concentrada o dispersa, a la lectura del texto, el cual puede variar grandemente en calidad y del cual podrá sacar mucho o poco provecho dependiendo de las aptitudes lectoras que tenga para ello. Esa lectura podrá llevarla a cabo en cualquier lugar y seguirá siendo un acto cotidiano en el que en ningún momento, o tal vez en alguna fugaz ocasión, se preguntará por el sentido de la lectura. Y al decir sentido no se hace referencia a lo que puede el lector extraer de la lectura misma, el sentido de lo que contiene el texto. Los filósofos dirán: al ser o a la esencia de la lectura. El lector, en primera y hasta en última instancia, sólo quiere leer el libro que sea de su interés y en cuanto tal para él la lectura tiene una constitución unidimensional y, por ende, diremos, es un objeto que le presenta una visión plana y limitada de sus propiedades y relaciones.

El bibliotecario, que en algunos casos no tan comunes suele ser también un lector, observa exteriormente la lectura de aquellos que acuden a la biblioteca, con lo que para él comienza la lectura a ser un objeto de conocimiento. Él representa el punto de transición de la lectura que va de objeto 
fáctico a objeto de conocimiento. El bibliotecario comprende la lectura desde el marco de referencia de sus propias actividades en la biblioteca, así como de las funciones que en ésta se llevan a cabo, como la selección, catalogación, ordenación, difusión y análisis de la información. ${ }^{1}$ De este marco de referencia brota su concepción del lector y de la lectura: el primero queda poseído por ese espectral concepto de usuarios de la información, que acaba por hacer que el lector desaparezca entre la bruma de la abstracción. Y la lectura se reduce, simplifica, a un proceso de succión de la información contenida en los materiales de la biblioteca. Así la lectura, para el bibliotecario, en cuanto objeto de conocimiento, queda cercada dentro de la ecuación: informaciónusuario-libro. El bibliotecario con semejante concepción de la lectura, que finalmente es consustancial a la Bibliotecología en boga, ha comprendido el mayor número de escorzos que le muestra este objeto de conocimiento, y de este modo ha suministrado el basamento para la posterior elaboración multidimensional que llevará a cabo el bibliotecólogo, pero aun así tal visión de la lectura es oblicua, lo que ha redundado en una concepción esquemática, por no decir deshumanizada de ella.

El bibliotecólogo dedicado en pleno a la actividad cognoscitiva de investigación y que elige, dentro de las configuraciones sobre las que se centra el conocimiento bibliotecológico, la lectura como su objeto de estudio, lleva a cabo la trasmutación de éste en objeto de conocimiento, su objeto de conocimiento, que queda así integrado en la constelación de los demás objetos de la disciplina con los que establece un complejo de relaciones específicas. La lectura queda así integrada dentro del estatuto epistemológico de la disciplina; es decir, que es comprendida, estudiada, desde el paradigma de la misma. Pero al ser la Bibliotecología una disciplina de convergencia disciplinar, se utilizan recursos de otras disciplinas para profundizar y fundamentar mejor su propia concepción básica de la lectura. Así el bibliotecólogo partiendo de una concepción primaria, análoga a la del bibliotecario, con cada aporte de otra disciplina que incorpora a su objeto de conocimiento lo va ampliando en su multidimensionalidad. La lectura legitimada por completo como objeto de conocimiento de la Bibliotecología muestra ahora mayor cantidad de escorzos, propiedades y relaciones, y se torna así más compleja y problemática, sinónimo de riqueza temática. Cada integración que se hace de los elementos de otra disciplina se constituye en la base de un nuevo escorzo. Y cada nuevo escorzo abre nuevos problemas, esto es, nuevos interrogantes y territorios por contestar y explorar. Y así la lectura, que en su estatus de objeto aún fáctico

1 Froissart, F. et Hecquard, F. (coordination), Le métier de Bibliothécaire, París, Editions du Cerele de la Librairie, 1993. 
parece no mostrar mayores problemas para el lector, sobre los que presenta el mismo acto inmediato de leer el texto, desde la óptica del objeto de conocimiento bibliotecológico se ha tornado extremadamente complejo. Cada frente de problemas que abre la presencia de un nuevo escorzo exige nuevas respuestas, es decir, otros aportes de otras disciplinas, o de una misma disciplina ya integrada antes otros elementos no contemplados previamente. ${ }^{2}$

En el caso de la lectura, el problema sustancial que se pone de manifiesto es cómo ésta constituye al individuo, esto es, cómo a partir de la información y el conocimiento que la lectura le suministra, lo conforma en múltiples dimensiones, lo cual a su vez incide directamente en el nódulo de una controversia central en la disciplina bibliotecológica: la disyuntiva entre conocimiento humanístico o técnico. Controversia que en el fondo se asienta sobre un falso problema. La técnica es y siempre será un simple medio auxiliar y, por ende, es sólo un instrumento al servicio de las actividades humanas. Es más, su mero ser instrumental pone de manifiesto la esencialidad humana. Convertirla en un fin, desubicándola de su exclusiva posición de medio, es dejarse engañar por un espejismo tendencioso que pone al mundo de cabeza. $\mathrm{La}$ Bibliotecología es en esencia un conocimiento bumanístico y basta social, pero no sólo técnico como han argumentado con atingencia y precisión algunos bibliotecólogos. $^{3}$

La problemática de la lectura lo que en el fondo hace es terminar de despejar las brumas del mencionado falso problema para dejar claramente establecido el estatus humanístico de la disciplina. El lector es antes que nada un ser humano; es decir, algo más que un mero usuario de la información, alguien que confirma y reafirma su humanidad en la misma práctica de la lectura; más para llegar a esta conclusión fundamentándola, el bibliotecólogo ha de recurrir a los aportes que le brindan la Sociología, la Historia, la Psicología y demás disciplinas que tengan algo que decirle sobre la lectura,

2 Ubicándonos en el terreno concreto, puede cuestionarse que tal integración de aportes de otras disciplinas para tornar multidimensional a la concepción bibliotecológica de la lectura no la puede llevar a cabo ningún bibliotecólogo por lo descomunal que tal empresa significa, puesto que el solo hecho de abrir un nuevo escorzo a partir de los aportes de una sola disciplina ya conlleva en sí mismo la consumición de gran parte de la trayectoria intelectual de un bibliotecólogo, y por tanto no puede abarcar más escorzos. Tal argumento puede ser cuestionado desde otra perspectiva, pero lo que se ha de especificar es que con lo anteriormente expuesto se enfoca desde la perspectiva de conjunto de la disciplina, Cada investigador abre un escorzo con lo que toma de otra disciplina o, mejor aún, muestra otro escorzo del objeto de conocimiento, el cual pasa a integrarse, relacionarse, con los escorzos previamente mostrados por bibliotecólogos anteriores o coetáneos. Y todo ese conjunto de escorzos conforma el bagaje de conocimientos que en la disciplina se tienen sobre la lectura. Asimismo de tal bagaje se puede conformar y extraer una visión unitaria de tal objeto de conocimiento, que exhibe problemas sustanciales que se corresponden con aspectos centrales de la disciplina.

3 Rodríguez Gallardo, Adolfo, Formación bumanistica del bibliotecólogo: hacia su recuperación, México, UNAM-CUIB, 2003. 
por lo que ha de mostrar sin tregua nuevos escorzos de tal objeto de conocimiento, porque además lo humano no es una entidad estática e inmutable: su destino es la mutación perpetua hacia la completa e integral realización de lo humano, que finalmente conduce a su liberación. Por eso la lectura susurra la esperanza libertaria de lo humano.

En lo que viene a continuación propongo mostrar otro escorzo, el cual tiene la peculiaridad de tener una dimensión contradictoria con lo que previamente han mostrado otros escorzos, por lo mismo es el que mejor completa esos escorzos con lo que da un paso adelante en la formación de una visión más integral de la práctica de la lectura, al mismo tiempo que le otorga una concepción más amplia de la humanidad del lector. Tal escorzo se funda en los aportes de una disciplina de la que la bibliotecología ha llegado a tomar elementos, la Psicología, pero ahora se tomarán de otro escorzo de ella, el psicoanálisis. Lo que nos permitirá conocer la otra lectura, la que se lleva a cabo entre los intersticios profundos de la psique del lector.

La figura del lector y la práctica de la lectura que éste ejerce y lo define son objetos de conocimiento primordiales para la disciplina bibliotecológica, de ahí la necesidad de que para tener una más amplia y profunda comprensión de sus escorzos se recurra a disciplinas para las cuales éstos son también objetos de conocimiento, aunque para estas disciplinas no sean objetos de conocimiento importantes, sino periféricos o tangenciales, correlativos a sus temas centrales. Por eso en la medida que para la Bibliotecología son centrales estos escorzos pueden ser elaborados y reelaborados, es decir, comprendidos y fundamentados a profundidad para así devolvérselos a aquellas disciplinas de las que tomaron algunos elementos para explicarlos. Con esto la Bibliotecología deja de manifiesto la dinámica de su funcionamiento como disciplina de convergencia disciplinar.

Las disciplinas de las que la Bibliotecología ha tomado elementos específicos en mayor medida para dejar que se muestren más escorzos de la lectura son la Sociología, la Historia y la Psicología, disciplinas esencialmente sociohumanísticas, lo que significa que tienen al ser humano, sea en su vertiente colectiva o individual, como objeto de conocimiento. Por lo mismo no es gratuita la recurrencia de la Bibliotecología a ellas, nexos profundos las hermanan.

La Sociología le ha expandido la mirada a la Bibliotecología, y le ha permitido comprender un mayor número de propiedades y relaciones sobre la lectura, aquellas que se extienden al ámbito social. El lector no sólo se reduce al ejercicio de la lectura dentro del ámbito bibliotecario puesto que cada lector es expresión y representación de la colectividad. La lectura es una práctica social. Detrás de cada lector solitario está la sociedad; por lo que la práctica de la lectura individual es el eco de toda la colectividad que pone en 
marcha esa práctica. La lectura trasciende así las miras de la biblioteca y en cada lector individual que penetra en una biblioteca está la presencia social.

La Historia le ha suministrado a la Bibliotecología el aire del tiempo. Le ha dado la visión de que el lector y la lectura no son entidades inmutables, asépticas a los cambios sino todo lo contrario, que están expuestas a las transformaciones que impone cada época según las características definitorias de la época histórica involucrada. Características que determinan la forma de leer y hasta la organización del texto. Pero el lector no es tampoco presente puro dentro de la biblioteca, ni la lectura es en sí un acto proscrito del tiempo, de la historia.

La Psicología introduce a la Bibliotecología en los procesos psíquicos que se llevan a cabo en la lectura y las consecuencias que eso acarrea en el lector. Muestra la dimensión individual e interna de la lectura, denotando las formas de asimilar la información contenida en los textos y el modo en que ello contribuye a la elaboración de los mecanismos del pensamiento y, por ende, a la visión que el individuo construye de su realidad. Contrariamente a los aportes que brinda la Sociología, donde se amplifica la visión del lector y la lectura como entidades sociales, con la Psicología, la visión se contrae hasta el interior de la conciencia individual.

Pero más allá de las diferencias de visión (parámetro de realidad) que esas tres disciplinas tienen respecto al mismo objeto de conocimiento, éstas coinciden con el supuesto fundamental de la lectura como un acto clara e indiscutiblemente racional y, por consiguiente, del lector como individuo consciente, puesto que sólo desde la posición racional se puede llevar a cabo la práctica lectora. Supuesto con el que, obviamente, comulga también la visión bibliotecológica; sin embargo, desde los aportes que emplearé del psicoanálisis, tal supuesto parece ponerse en duda: lo que nos permitirá mostrar un rastro oculto de la lectura, lo cual más que ser en sí una visión contradictoria respecto a las mencionadas disciplinas, como veremos, las complementa enriqueciéndolas, dando con ello una visión más completa y humanística del lector y la lectura, que ha de recuperarse para la Bibliotecología.

Pocas fueron las reflexiones que Freud hizo sobre la lectura a lo largo de su obra completa, lo que es de lamentar sabida la fama que tenía de gran lector, lo cual se denota en su obra por la riqueza de información, así como por la cantidad y calidad de autores de los que se nutrió. Es obvio que para él la lectura no era un problema que mereciera tratarse por sí mismo sino sólo circunstancialmente con relación a los problemas centrales del psicoanálisis; lo cual no es un menoscabo sino todo lo contrario, aquí la escasez es un estímulo para la búsqueda. Por el carácter mismo de esas breves reflexiones semejan puertas entornadas que anuncian el esplendor de lo que hay dentro, invitándonos a entrar. 
Fuera de fugaces menciones sobre la lectura con que salpica algunos de sus textos, la más "perfilada" reflexión que lleva a cabo Freud sobre ella se encuentra en su libro Psicopatología de la vida cotidiana, en un capítulo breve de título indicativo del tratamiento que da al tema: "Equivocaciones en la lectura y en la escritura". Y de hecho la sección concerniente a la lectura es más corta que la que trata sobre la escritura. Años después, en la obra Introducción al psicoanálisis, Freud vuelve a tratar el tema pero aún más brevemente y repitiendo su argumentación de base. Veamos cual es su argumentación al respecto. Después de exponer en el mencionado capítulo varios ejemplos de las equivocaciones que se presentan en el momento de leer, en algunos de esos ejemplos Freud es el protagonista (lo que es de resaltar porque él mismo observa su propia actividad lectora reflexionando sobre ella, por lo que vive el tránsito de la lectura como objeto fáctico a objeto de conocimiento), su tesis puede sintetizarse en que las equivocaciones que cruzan y dispersan la lectura son de dos grupos, el primero tiene causa en el lector y el segundo en el texto. Sobre la primera causa explica:

En una numerosísima cantidad de ejemplos, es la predisposición del lector lo que transforma el texto a sus ojos, haciéndole leer algo relativo a los pensamientos que en ese momento le ocupan. El texto mismo no necesita coadyuvar a la equivocación más que presentando alguna semejanza en la imagen de las palabras, semejanza que pueda servir de base al lector para verificar la transformación que su tendencia momentánea le sugiere. El que la lectura sea rápida y, sobre todo, el que el sujeto padezca algún defecto, no corregido, de la visión, son factores que coadyuvan a la aparición de tales ilusiones, pero no constituyen en ningún modo condiciones necesarias. ${ }^{4}$

Es frecuente, según Freud, que cuando leemos un texto cambiemos unas palabras por otras, pero no cualquier palabra sino palabras muy precisas, aquellas que tienen "alguna semejanza" con las palabras que ocupan el pensamiento del lector en el momento de leer el texto. Esto significa que durante el acto consciente de la lectura en el lector se desarrolla simultáneamente un proceso interior, y que ambos están signados por una serie de parpadeos que hace que se crucen, interfiriéndose, lo que produce la equivocación, haciéndole al lector "leer algo relativo a los pensamientos que en ese momento le ocupan"; en suma, el lector proyecta sobre el texto su universo interior que tiene como anclaje ciertas palabras, las cuales son transformadas, equivocadas, según lo que ese universo interior le dicta o más exactamente le impone

4 Freud, S., Psicopatología de la vida cotidiana, en Obras Completas, vol. I, Madrid, Biblioteca Nueva, 1948, p. 691 
al texto cambiándolo. El otro grupo de equivocaciones tiene causa en el propio texto y de ello nos dice Freud:

Existe un segundo grupo de casos en el que la participación del texto en el error que se comete en su lectura es más considerable. En tales casos, el contenido del texto es algo que provoca una resistencia en el lector o constituye una exigencia o noticia dolorosa para él, y la equivocación altera dicho texto y lo convierte en algo expresivo de la defensa del sujeto contra lo que le desagrada o en una realización de sus deseos. Hemos de admitir, por tanto, que en esta clase de equivocaciones se percibe y se juzga el texto antes de corregirlo, aunque la conciencia no se percate en absoluto en esta primera lectura. ${ }^{5}$

Como puede apreciarse por las palabras supracitadas, este grupo de equivocaciones en la lectura es el recurso y complemento del anterior; pero entraña que "el error que se comete en su lectura es más considerable" porque pone mayormente de manifiesto la problemática interna del lector. Si en el primer grupo de equivocaciones comienza a insinuarse esa problemática interna, en este otro grupo queda abiertamente manifiesta esa otra dimensión que discurre simultánea al acto consciente de lectura y que está surcada por contradicciones que brotan en la confrontación con el contenido del texto, que desencadena situaciones dolorosas ante las cuales se resiste el lector defendiéndose ${ }^{6}$ e incluso, a través de la equivocación en la lectura, convirtiendo al texto en una realización de sus deseos. Es de suma importancia para el desarrollo de mi argumentación retener esto último: el texto como ámbito de deseos y placer.

Para Freud hay, pues, dos grupos de equivocaciones que se presentan en la lectura y que conforman una especie de desencuentro entre el lector y el texto. Pero finalmente ambos grupos de equivocaciones más allá de sus particularidades y complementariedades, las reduce Freud a aquellas manifestaciones psíquicas que define como lapsus, los cuales son puestos en evidencia a través de esos parpadeos que se dan en el fluir de la vida interior. En ese libro, síntesis de su obra, que es Introducción al psicoanálisis Freud aparte de repetir su argumento sobre la lectura agrega una indicación al lector para que él mismo inicie el análisis de esos lapsus:

5 Ibídem

6 Idea que reafirma años después: "Las equivocaciones en la lectura nos ofrecen también abundantes ejemplos, en los que la tendencia perturbadora es despertada por el mismo texto de nuestra lectura, el cual queda entonces transformado, la mayor parte de las veces, por dicha tendencia en su contrario. Tratase casi siempre en estos casos, de textos cuyo contenido nos causa displacer, y el análisis nos revela que debemos hacer responsable de nuestra equivocación en su lectura al intenso deseo de rechazar lo que en ellos se afirma". Freud, S., Introducción al psicoanálisis, en Obras Completas, vol. II, Madrid, Biblioteca Nueva, 1948, p. 91. 
Si se quiere descubrir la tendencia perturbadora causa del error, debe dejarse por completo a un lado el texto falsamente leído e iniciar el examen analítico con las dos interrogantes siguientes: $1^{a}$. ¿Cuál es la primera idea que acude al espíritu del sujeto y que se aproxima más al error cometido? $2^{\mathrm{a}}$. ¿En qué circunstancias ha sido cometido el error? A veces, el conocimiento de la situación basta para explicar el error. ${ }^{7}$

Mas para comprender mejor esto es conveniente contextualizar tales lapsus de la lectura dentro del texto en que están primeramente expuestos, así como en el conjunto de la obra freudiana.

Como ya se mencionó, la reflexión que hace Freud sobre las equivocaciones en la lectura ocupa un rincón del libro Psicopatología de la vida cotidiana, en el cual rastrea y explica todos aquellos olvidos, equivocaciones, torpezas, errores y hasta caídas que cometemos en la vida cotidiana y que él define bajo el rubro genérico de actos fallidos. Estos actos "aparentemente sin importancia" se presentan con constancia tenaz a lo largo de nuestros días cotidianos, que de tan usuales incluso llegan a pasar inadvertidos. Sólo suceden y no pasa nada de consideración, fuera de un leve percance que se desvanece entre la espuma de los días. Pero fue aquí en tales percances nimios y circunstanciales que la mirada incisiva de Freud contempló la profundidad de lo que había debajo de ellos, con lo que los dotó de un sentido antes no imaginado. Esa constelación de actos fallidos tiene, pues, un sentido claro, el cual está radicado en ese crucial descubrimiento freudiano: el inconsciente.

Cuando Freud escribe el libro Psicopatología de la vida cotidiana ya ha vislumbrado con mayor precisión esa dimensión profunda de la psique y gradualmente ha ido cercándola. ${ }^{8}$ En este libro, su acoso al inconsciente lo lleva a partir de las huellas que deja en la vida cotidiana, esto es, en esos rastros patológicos que va dejando en las actividades individuales cotidianas. Lo que lo conduce a deducir que los actos fallidos son producto de un mecanismo psíquico: la represión, que pone límite a una serie de impulsos (que posteriormente definirá como pulsiones de las que incluso especificará dos: de vida y muerte) que pugnan por externarse, por encontrar satisfacción en la realidad inmediata, pero que al ser reprimidos encuentran forma de manifestarse a través de los actos fallidos, lapsus que introducen estridencia en la balada de la vida consciente. Lo que para nuestro tema en particular viene a significar que el acto consciente, racional de la lectura se despliega sobre una tenue capa de cristal ahumado que en cualquier momento se astilla o se

$7 \quad$ Ibid., p. 90.

8 Quindoz, Jacques-Michel, Lire Freud. Décuverte Chronologique de l'oeuvre de Freud, París, PUF, 2004. 
rompe dejando ver en el fondo la otra lectura, la que esta permeada por las fuerzas del inconsciente.

Los actos fallidos son, pues, actos pletóricos de sentido que ponen en evidencia, por medio de los yerros en la vida cotidiana, la rica y abismática vida subterránea del individuo, pero también ponen de relieve la amplia problemática de la relación del inconsciente con la lectura. Lo que abre la cuestión sobre la forma en cómo la lectura ha sido concebida a través de la historia y la parte de ella que ha dejado oculta esa historia. Veamos ahora esa problemática con detalle a partir de lo que nos aportan los elementos centrales de la teoría psicoanalítica de Freud.

El poder plástico y arquitectónico de la mente de Freud construyó una visión, una estructura, del universo interior del individuo que denominó aparato psíquico; el cual fue diseñado, depurado y perfeccionado a lo largo de toda su carrera intelectual. La gran cualidad explicativa de esa estructura psíquica radica en buena medida en su visualidad tópica; esto es, en un esquema de alegoría espacial psíquica cuyos componentes están claramente perfilados y ubicados en un lugar preciso desde donde interactúan dinámicamente. Muy semejante en ese sentido a la visión estructural de Marx sobre la sociedad compuesta de infraestructura económica y superestructura ideológica. Esto fue factor decisivo para el impacto social y cultural que tuvo el psicoanálisis, lo que además contribuyó para atraer a toda una caterva de continuadores y practicantes. Tal aparato psíquico se compone de tres instancias psíquicas: Ello, Yo y Superyó; las cuales en sí mismas son la denominación dada a sistemas de la psíque humana implícitas en esas instancias. El ello contiene el sistema del inconsciente; mientras que el yo contiene los sistemas pre-consciente y consciente. El superyó es un desdoblamiento del yo como un sistema con cualidades propias y funciones precisas. ${ }^{9}$ Veamos brevemente la particularidad de cada una de tales instancias psíquicas.

El inconsciente es el sistema primigenio de donde se desarrollará posteriormente el conjunto del aparato psíquico. Es una realidad psíquica divergente de la realidad material y cuyo núcleo está constituido por representaciones y pulsiones; esto es, emociones y deseos que subsisten conjuntamente para alcanzar una meta fijada. Este núcleo de pulsiones es semejante al instinto de los animales; conforme el individuo crece y se inserta más sólidamente en la vida social el inconsciente recibe todo lo que ha sido rechazado como inutilizable por los requerimientos sociales. Así el individuo en aras de desplegar una vida social en términos funcionales aceptando los códigos que la convivencia social establece, rechaza una parte psíquica muy importante de

9 Para una sintética y precisa explicación de los términos y conceptos del psicoanálisis véase: Laplanche, J., et Pontalis , J. B., Vocabulaire de la psychanalyse, París, PUF, 2002. 
él que pasa a integrarse al núcleo originario de su inconsciente. La tendencia intuitiva, pulsional, del inconsciente se agita y responde a excitaciones tanto internas como externas y en cuanto tal busca un objeto y una finalidad. El objeto no necesariamente es exterior ni único: puede regresar de un objeto a otro anterior o suplantar un objeto por otro; esto es, de ser un objeto exterior puede constituirse en un objeto interior que pasa a ser una entidad integrada a la realidad psíquica inconsciente, cuando el objeto material que fue el referente inicial ha salido de la vida del individuo. En cuanto a su finalidad el instinto busca la satisfacción en ese objeto. Tal búsqueda de satisfacción la definió Freud como principio del placer. ${ }^{10}$ Como se verá más adelante el principio del placer tiene un papel central en el proceso de la lectura.

Gradualmente Freud afinó su concepción de los instintos hasta concebirlos como una energía constituida centralmente por dos grandes tendencias: Eros o instinto de la vida, que conlleva la instintualidad de conservación del individuo y de la especie, que pueden traducirse en amor a sí mismo y amor objetual, ambos se oponen uno al otro. A la energía de este instinto en su forma unitaria la designa Freud como libido. El otro es el instinto de destrucción o de muerte, cuyo fin es destruir todo objeto y regresar así lo viviente al estado inorgánico. Cuando este instinto, por los mecanismos de la represión, no puede descargarse en el exterior como agresión a través del impulso muscular, se revierte esa agresividad hacia el interior convirtiéndose en autoagresividad la cual puede incluso llegar a destruir al individuo. Contra eso la libido lleva a cabo la función de neutralizar tales tendencias destructivas. ${ }^{11}$

El inconsciente contiene una especie de sabiduría que le dice que no todo instinto puede ser satisfecho por el principio del placer, por lo que esos instintos sin satisfacción, reprimidos, pasan a ser parte importante de los contenidos del propio inconsciente. Son la parte del Ello que se denomina lo reprimido. ${ }^{12}$ Pero lo reprimido es testimonio de la servidumbre del inconsciente al principio del placer. El otro contenido del inconsciente son las representaciones que tienen como función revestir las pulsiones para darles una identificación, de lo contrario sin ese revestimiento las pulsiones sólo se

10 "Príncipe régissant le fonctionnement psychique, selon lequel l'activité phychique a pour but d'eviter le déplaisir et procurer le plaisir". Chemama Roland (direction) Dictionnaire de la psychanalyse, París, Larousse, 1993, pp.211-212.

11 "Los peligrosos instintos de muerte son tratados en el individuo de muy diversos modos. Parte de ellos queda neutralizada por su mezcla de componentes eróticos; otra parte es derivada al exterior, como agresión y una tercera, la más importante, continua libremente su labor interior." Freud, S., El 'Yo' y el 'Ello', O. C. Vol. I, ed. cit., p. 1232

12 "Así, pues, nuestro concepto de lo inconsciente tiene como punto de partida la teoría de la represión. Lo reprimido es para nosotros el prototipo de lo inconsciente. Pero vemos que se nos presentan dos clases de inconsciente: lo inconsciente latente, capaz de conciencia, y lo reprimido incapaz de conciencia”. Ibid., p. 1075. 
presentan como meras afecciones. Lo que viene a significar que las representaciones conllevan un impulso de organización y comunicación fundamental para la manifestación del inconsciente. Esto es destacable porque entraña la simiente del potencial lingüístico del individuo, por lo que asimismo es un enclave profundo para la palabra de la lectura. Freud resume las cualidades del sistema inconsciente de esta manera:

Los procesos del sistema Inc. (Inconsciente) se hallan fuera del tiempo, esto es, no aparecen ordenados cronológicamente, no sufren modificación alguna por el transcurso del tiempo y carecen de toda relación con él. También la relación temporal se halla ligada a la labor del sistema Cc. (Consciente). Los procesos del sistema Inc. carecen también de toda relación con la realidad. Se hallan sometidos al principio del placer y su destino depende exclusivamente de su fuerza y de la medida en que satisfacen las aspiraciones de la regulación del placer y el displacer. Resumiendo, diremos que los caracteres que esperamos encontrar en los procesos pertenecientes al sistema Inc. son la falta de contradicción, el proceso primario (movilidad de las cargas), la independencia del tiempo y la sustitución de la realidad exterior por la psíquica. ${ }^{13}$

La imagen que se desprende de las palabras supracitadas respecto al inconsciente es de un ámbito psíquico signado por la eternidad y recorrido por la luminiscencia del deseo. En el inconsciente no existe el tiempo ni las contradicciones. Esas mismas características son precisamente las que posibilitan la gestación en el inconsciente de lo imaginario (y con éste sus formas de actualización: la imaginación y la fantasía) y el despliegue que a partir de él lleva a cabo la creatividad. Por eso el inconsciente más allá de ser un mero depósito de pulsiones es una fuente de potencialidades creativas y de crecimiento que pueden liberarse para que el individuo las canalice a través de su acción sobre la realidad. Mas para llevar esto a realización se requiere recorrer un intrincado camino de maduración, en el que la lectura puede jugar un papel importante.

El yo se compone de los sistemas consciente y pre-consciente. La conciencia es la parte del yo que se encuentra focalizada hacia el mundo exterior, mientras que el preconsciente es aquel que establece la conexión con el mundo interior, es una especie de entidad fronteriza donde se cruzan las funciones del inconsciente y del consciente. La conciencia surge del inconsciente como un proceso de diferenciación a partir del contacto de éste último con el mundo exterior. Es como si con esa diferenciación el mismo inconsciente 
pusiera límite a su poder pulsional, puesto que mientras él está determinado por el principio del placer el consciente esta signado por el principio de la realidad, que es limitador de las satisfacciones que aquél busca. Por eso, visto en conjunto, el yo es la contracara del ello; sus funciones son distintas, al grado de que pueden establecer fuertes confrontaciones, pero a la vez complementarios como una necesidad de supervivencia del individuo:

Fácilmente se ve que el Yo es una parte del Ello modificada por la influencia del mundo exterior, transmitida por el P-ce (Pre-consciente), o sea, en cierto modo, una continuación de la diferenciación de las superficies. El Yo se esfuerza en transmitir a su vez al Ello dicha influencia del mundo exterior, y aspira a sustituir el principio del placer, que reina sin restricciones en el Ello, por el principio de realidad. La percepción, es para el Yo, lo que para el Ello el instinto. El Yo representa lo que pudiéramos llamar la razón o la reflexión, opuestamente al Ello, que contiene las pasiones. ${ }^{14}$

El yo en su sistema consciente asegura la autoconservación del individuo, a partir de conocer y mediar las excitaciones que el mundo exterior envía; esto es, evitando (por la fuga) las excitaciones demasiado fuertes y adaptándose a las excitaciones moderadas, ejerciendo a la vez la acción sobre el mundo exterior en su provecho.

Hacia el interior, utilizando por momentos la mediación del preconsciente, emprende la acción de contención y administración de las pulsiones, decidiendo hasta que punto deben ser satisfechas; esto con base en su evaluación de las tensiones que provocan las excitaciones interiores y exteriores: cuando se acrecientan provocan desagrado y cuando disminuyen, placer. Resumiendo, las características definitorias del yo como sistema consciente son: el ser un mediador entre la realidad exterior e interior. En esa función, función mediadora, impone restricciones al principio del placer a través del principio de realidad. Pero sobre todo cabe resaltarse que en él se lleva a cabo la actividad racional, reflexiva, opuesta a las pasiones propias del inconsciente. Actividad racional de carácter lógico que por lo mismo se desenvuelve en la temporalidad social inmediata e histórica. El ámbito propio de la conciencia es el del tiempo exterior cronológico. En estas actividades el yo es apoyado, complementado por el pre-consciente, el cual de esa forma modula la relación entre el inconsciente y la conciencia, paralelamente a como ésta última modula la relación entre el mundo exterior y el mundo interior; en palabras de Freud: 
Al sistema Prec. le corresponden además, la constitución de una capacidad de relación entre los contenidos y la introducción de una o varias censuras del examen de la realidad y del principio de la realidad. También la memoria conciente parece depender por completo del sistema Prec. ${ }^{15}$

En cierto modo el preconsciente es un amortiguador de los antagonismos y tensiones que se dan entre el ello y el yo, y donde se denota con mayor precisión esa función es en el papel que juega el yo en la elaboración de los sueños. En el pre-consciente se reelaboran los contenidos pulsionales articulando las representaciones con que son revestidos. La intemporalidad del inconsciente pasa a través del cedazo de la temporalidad que le suministra el pre-consciente; lo que asimismo implica una administración de la censura que le aplica el principio de la realidad al principio del placer. Pero lo que interesa destacar para los fines de mi argumentación es que el preconsciente actualiza lingüísticamente el potencial comunicativo del inconsciente, y que al cruzar las pulsiones a través de él, adquieren voz. Las imágenes consustanciales de las representaciones con que buscan externarse las pulsiones son acabadas de configurar por la palabra, esencial al preconsciente. Palabra que permite la externalización lingüística del inconsciente; ${ }^{16}$ por eso los sueños pueden comunicarse verbalmente.

Así como el yo es producto de una diferenciación del ello cuando entra en contacto con la realidad, de manera análoga y en una etapa de la vida del individuo cercana a aquella en que se dio esa diferenciación, el superyó es resultado de una diferenciación del yo a partir de la suma de identificaciones del individuo con sus padres y con todas las sucesivas figuras de autoridad que se introyectan en su conciencia. Cuando el niño se ve obligado, por su propio desarrollo, a renunciar a un objeto (sexual) con el que se identifica el yo se transfigura encontrando, constituyendo, dentro de sí mismo ese objeto perdido, lo que facilita la renuncia al objeto exterior; de esta manera se da la introyección y en cuanto tal la instauración del superyó, cuya función es ser la conciencia moral censora del Yo:

15 Freud, S., Metapsicología, ed. cit., p. 1047.

16 “Cómo hacer para 'hacer conscientes algunas cosas’? Habrá que preguntarse primero: ¿Cómo se vuelve preconsciente una cosa'? Gracias a la asociación con las representaciones verbales correspondientes. Hay que precisar que se trata sobre todo de percepciones acústicas (huellas mnésicas de la palabra escuchada). Por consiguiente, se llevarán a la conciencia los elementos reprimidos restableciendo mediante el trabajo analítico de esos miembros intermediarios inconscientes que son los recuerdos verbales. De ahí la extrema importancia del lenguaje y de la semántica en el conocimiento del inconsciente". Hesnard, A., La obra de Freud, México, FCE, 1972, p.71. 
El Súper-Yo conservará el carácter del padre, y en cuanto mayores fueron la intensidad del complejo de Edipo y la rapidez de su represión (bajo las influencias de la autoridad, la religión, la enseñanza y las lecturas), más severamente reinará después sobre el Yo como conciencia moral o quizá como sentimiento inconsciente de culpabilidad. ${ }^{17}$ (cursivas mías)

Obsérvese en las palabras citadas que Freud señala las lecturas como parte de los mecanismos de la represión, sobre esto se hablará adelante. En primera instancia el superyó reproduce el carácter del padre, afirmándolo por un lado y rebelándose contra él por el otro lado, ${ }^{18}$ y a esa primera figura de poder introyectada se suman otras autoridades más imponiéndosele al yo a través de los escrúpulos de la conciencia, lo que desencadena el sentimiento y el comportamiento inconsciente de culpabilidad. Así el superyó es moldeado por la figura del padre y sucesivas figuras de autoridad, lo que asimismo viene a significar la introyección a través de esas figuras del conjunto de la organización y mecanismos de dominación sociales, que incluso se presentan como ciertos ideales que exigen ser respetados, ${ }^{19}$ pero que pueden también convertirse en un yo ideal que empuje al individuo a la aspiración de cosas superiores.

Con la descripción anterior de las instancias psíquicas, en sí esquemática, en aras de resaltar lo que es pertinente para la argumentación aquí desarrollada, puede apreciarse la fina y estética arquitectura de la tópica con que Freud dio forma a la estructura de la psique; algo nunca antes concebido de esa manera, con lo que cambio la visión que se tenía de la psique humana, lo que asimismo vino a darle un giro a las ciencias humanas, reformulando con eso una concepción más profunda del ser humano y por ende, del humanismo. Pero esta arquitectura del aparato psíquico alcanza su plenitud explicativa cuando se la comprende desde su dimensión dinámica. Las tres instancias psíquicas (Ello, Yo, SuperYó) no son compartimentos autónomos y estáticos, todo lo contrario, es un ámbito que se constituye precisamente a partir de

17 Freud, S., El 'Yo' y el 'Ello', ed. cit., p. 1223.

18 "Pero el Súper-Yo no es simplemente un residuo de las primeras elecciones del objeto del Ello, sino también una enérgica formación reactiva contra las mismas. Su relación con el Yo no se limita a la advertencia: 'Así - como el padre- debe ser', sino que comprende también la prohibición: 'Así -como el padre- no debes ser': no debes hacer todo lo que él hace, pues hay algo que le está exclusivamente reservado." Ibíd., p. 1223.

19 "Situándose en el punto de vista de la restricción de los instintos, o sea de la moralidad, podemos decir lo siguiente: el Ello es totalmente amoral; el Yo se esfuerza en ser moral, y el SúperYo puede ser 'hipermoral' y hacerse entonces tan cruel como el Ello. Es singular que cuanto más limita el hombre su agresión hacia el exterior, más severo y agresivo se hace en su ideal del Yo, como un desplazamiento y un retorno de la agresión hacia el Yo. La moral general y normal tiene ya un carácter severamente restrictivo y cruelmente prohibitivo, del cual procede la concepción de un ser superior que castiga implacablemente.” Ibid., p. 1232 
un complejo entramado de interacciones; de hecho, tal entramado articula la vida psíquica de todo individuo. Según la manera en cómo se llevan a cabo las interacciones entre las instancias psíquicas, el individuo puede desarrollar una vida normal o derivar en enfermedades psíquicas.

La visión integral que se desprende de la actividad interactuante de las instancias psíquicas es la del individuo habitando entre dos mundos que se comunican conviviendo o conflictuándose de múltiples formas: un mundo exterior y un mundo interior. El exterior presionando por medio de estímulos y excitaciones al interior del individuo; ante eso buscan responder las pulsiones para encontrar satisfacción a sus deseos, con lo que son coherentes con la ley que las rige, el principio del placer. Pero esa satisfacción se encuentra que no todo es placer, también hay displacer: Para administrar esa satisfacción se encuentra el yo, instancia racional que es a su vez controlada por las coacciones del superyó, que reprime al principio del placer por mediación del principio de realidad:

Veamos ahora al Yo con todas sus energías y debilidades. Se halla encargado de importantes funciones; por su relación con el sistema de percepción, establece el orden temporal de los procesos psíquicos y los somete al examen de la realidad. Mediante la interpolación de los procesos mentales, consigue un desplazamiento de las cargas motoras y domina los accesos a la motilidad. Este dominio es, de todos modos más formal que efectivo. Por lo que respecta a la acción, se halla el Yo en una situación semejante a la de un monarca constitucional, sin cuya sanción no puede legislarse nada, pero que reflexionará mucho antes de oponer su veto a una propuesta del Parlamento. El Yo se enriquece con la experiencia del mundo exterior propiamente dicho y tiene en el Ello otra especie de mundo interior, al que intenta dominar. Sustrae libido de él y transforma sus cargas de objeto en formas propias. Con ayuda del Súper-Yo, extrae del Ello en una forma que nos es desconocida, la experiencia histórica en él acumulada. ${ }^{20}$

El frágil equilibrio del aparato psíquico frente al mundo y frente a sí mismo se realiza por medio de un sutil tejido entre cada una de las instancias psíquicas y la fluidez de las pulsiones entre ellas, y sus consiguientes coacciones y represiones, que las inhiben, las exteriorizan o las subliman. De donde deviene el hombre sano o enfermo, el constructor de civilización o destructor de ella.

De esta forma el legado de Freud es la visión de un ser humano signado por la fragilidad: abatido por sus instintos, para el que sus certezas racionales, 
que lo convertían en una divinidad (orgullo de un humanismo tradicional y ego-etno-céntrico) se han venido abajo, y con ello la noción de una normalidad racional que era su basamento se ha resquebrajado para exhibirlo también como un ser expuesto todo el tiempo a las enfermedades mentales. Pero a cambio de esa caída del pedestal nos dio una concepción del hombre más completa y profunda, cuyo realismo pone en evidencia los espejismos de un humanismo de falso optimismo, cegado ante las contradicciones que dan forma a lo más esencialmente humano. Humanismo escéptico y hasta desencantado pero que propugna realistamente por la elevación y superación del ser humano. Humanismo freudiano que en cuanto tal puede brindarle a la Bibliotecología un escorzo de lectura como una práctica esencialmente humana, con lo cual contribuirá a reforzar la recuperación de la senda humanista consustancial a la Bibliotecología, y que por un perturbado deslumbramiento técnico se ha extraviado momentáneamente.

Con profundas palabras que invitan a la reflexión y que abren por lo mismo puertas para ir más allá de ellas buscando nuevos sentidos, Roger Chartier nos dice:

La lectura no es sólo una operación abstracta de intelección: es puesta en juego de cuerpo, inscripción en un espacio, relación consigo mismo y con los otros. ${ }^{21}$

A contramarcha de una tradición que ha hecho de la práctica de la lectura una mera y exclusiva "operación abstracta de intelección”, Chartier nos hace un llamado para abrir la mirada y contemplar lo que hay más allá de esa limitada concepción de la lectura. Y a la vez implícitamente con ello nos está diciendo que detrás de esa tradición hay un ocultamiento, de lo que pudiera ser la parte más determinante y explicativa de la lectura "la puesta en juego del cuerpo". Pero no el cuerpo entendido dentro de esa constelación del discurso que ha hecho de la corporeidad un tejido de signos abstracto. Discurso que pretendiendo ser espejo de la concreción natural del cuerpo ha terminado por hacer de él una imagen eidética, en la que no se reconoce cuerpo alguno que siente en el mundo concreto. Discurso que creyendo que sustrae el cuerpo a una tradición negadora de él, negación concomitante al privilegiamiento de una racionalidad ideologizada, acaba por ser el último giro de tuerca de esa negación de la corporeidad.

Para evitar la ambigüedad de esa trampa, Chartier señaliza el arraigo de esa corporeidad en la concreción a partir de la "inscripción en un espacio".

21 Chartier, R., Elorden de los libros. Lectores, autores, bibliotecas en Europa entre los siglos XIVy XVIII, Barcelona, Gedisa, 1994, p.29. 
Pero un espacio cuyo carácter definitorio concreto se muestra a partir de la "relación consigo mismo y con los demás". El cuerpo no es una entidad aislada, a la manera cartesiana, de aquellos otros que pueblan el mismo espacio, de hecho decir espacio, en este caso social, entraña hablar de un ámbito que es en esencia relacional. El entramado relacional actualiza la concreción. Relaciones que se despliegan en dos direcciones: el individuo consigo mismo (soi meme) y con los otros. La concreción como condición de posibilidad del diálogo con uno mismo y con los demás. Es en este espacio concreto interrelacional donde debe ubicarse para su legibilidad al lector, o más exactamente, al cuerpo lector, nos dirá implícitamente Roger Chartier. Una vez llegados a ésta avanzada se impone dar el siguiente paso, aquel que nos lleva o nos regresa a Freud.

El cuerpo lector a que nos llevó la proposición de Chartier es en su concreción el espacio detentador del aparato psíquico de Freud. El cuerpo lector es asimismo cuerpo psíquico. Por vía de la concreción corpórea la lectura se hace presente en lo psíquico y lo psíquico recorre la lectura. Es un movimiento de carácter recursivo entre la lectura y lo psíquico donde lo causante se convierte en causado; lo cual se hace legible con una explicación de mayor detalle.

Cuando Freud señala que el yo es resultado de una diferenciación del ello al entrar éste en contacto con el mundo exterior, lo que nos está diciendo es que el individuo, en muy temprana edad, deja tras de sí su mundo autónomo pulsional, determinado exclusivamente y sin contención por el principio del placer para abrirse a las excitaciones y estímulos externos lo que, más allá de las connotaciones biologistas, puede traducirse en términos sociales como que el individuo se está configurando socialmente. El yo es también una instancia psíquica modelada socialmente para así responder a los requerimientos sociales. Lo que implica por otra parte que el principio de realidad que rige al yo es por lo mismo un mecanismo modelado socialmente. Los requerimientos sociales están sujetos a una normatividad, la cual ha de ser comprendida y asimilada por el yo para que pueda el individuo interactuar funcionalmente en y con la colectividad. Esta exigencia impulsa el desarrollo de los procesos de percepción de lo social y con ellos de la razón del individuo, pero esto acarrea que el individuo autoimponga una serie de regresiones a su instintualidad. La razón se convierte en un censor de empuje pulsional, al que hace pasar por la aduana del principio de la realidad. Principio que por ende está en consonancia con los elementos fundamentales y determinantes de la realidad social particular en que se ubica el individuo.

Situándonos en nuestro contexto específico vemos que las sociedades contemporáneas en su mayoría tienen como fondo histórico común el hecho de ser culturas escritas; esto es, culturas para las cuales la escritura es un factor 
central articulador de sus diferentes estructuras. Aquí se definirá a las sociedades asentadas principalmente sobre cultura escrita como sociedades textuales, para dejar con ello implícita la unidad de escritura y lectura que priva en ellas.

En las sociedades textuales, la palabra escrita adquiere un estatus de autoridad que se inscribe en cada resquicio de la vida cotidiana dirigiendo en buena medida la manera de pensar y actuar de los individuos, de la colectividad en conjunto. Lo cual redunda en una racionalidad emergente hecha a la medida para generar escritura y descifrarla con la lectura. Entre los sistemas consciente y preconciente del yo se lleva a cabo la emergencia de dicha racionalidad. El mundo social signado por la cultura escrita se caracteriza por ser un ámbito mediado por signos escritos. Cada gesto, movimiento, pensamiento, palabra e incluso rebeliones contra ese orden de cosas está permeado por la palabra escrita, la cual, por consiguiente, de múltiples maneras trasciende el breve marco de los soportes materiales que le son ofrecidos a su lectura para circular entre los individuos; los dispositivos característicos de la escritura pasan así a integrarse en la generalidad del espacio social. Espacio de "signos en rotación". De ahí que en tales sociedades incluso los analfabetos estén determinados por las condicionantes de la escritura, quizá no puedan leer un texto pero su mente se articula con categorías de la textualidad. El mundo social es, por tanto, un mundo impregnado de textualidad, mundo que de esa forma modela al yo. Los procesos cognitivos del yo están signados por la palabra escrita y leída, pero debajo de tales procesos se deja escuchar el fragor pulsional del inconsciente. Fragor que es impedido de ir más allá de esa mostración subrepticia de su presencia.

Las sociedades textuales sólo ven y aceptan como fundantes de sí mismas la parte racional que genera la escritura y la lectura. Racionalidad de estas dos prácticas que, en cuanto tales, se erigen en basamento de una racionalidad más amplia que le da forma al conjunto de las estructuras sociales. Lo que hace que la concepción de tal racionalidad sea pilar inconmovible que les da seguridad y solidez a estas sociedades. Asimismo la "cosmovisión" e ideología de las sociedades textuales es eminentemente racionalista. De ahí que esta tendencia social llevada al terreno de la psicología sólo se haya centrado en los procesos psíquicos de la conciencia, sustentación de la racionalidad del yo, sin querer ver la dimensión inconsciente. Esto lo comprendió con claridad el propio Freud, como argumentó al defender lo que en ese momento había mostrado el psicoanálisis y quería ser acallado por el orden social:

La primera de tales extrañas afirmaciones del psicoanálisis es la de que los procesos psíquicos son en sí mismos inconscientes, y que los procesos conscientes 
no son sino actos aislados o fracciones de la vida anímica total. Recordad con relación a esto que nos hallamos, por el contrario, acostumbrados a identificar lo psíquico como lo conciente, considerando precisamente la conciencia como la característica esencial de lo psíquico y definiendo la Psicología como ciencia de los contenidos de la conciencia. Esta identificación nos parece tan natural que creemos hallar un absurdo manifiesto en todo aquello que la contradiga. Mas, sin embargo, el psicoanálisis se ve obligado a oponerse en absoluto a esta identidad de lo psíquico y lo conciente. Para ello lo psíquico es un compuesto de procesos de la naturaleza, del sentimiento, del pensamiento y de la voluntad, y afirma que existen un pensamiento inconsciente y una voluntad inconsciente. ${ }^{22}$

Qué más atentatorio contra el desideratum de racionalidad que afirmar que "los procesos conscientes no son sino actos aislados o fracciones de la vida anímica total". Lo que era de manera natural una norma y un continuo resulta que es parpadeante y aislado. Y además lo psíquico ha sido despojado de su trono absolutista de lo conciente para obligarlo a la aceptación democrática de sus propios contenidos, en gran medida emanados del inconsciente. Pero aceptar esto significaba y sigue significando un cuestionamiento de base a los fundamentos sobre los que se han levantado las sociedades textuales. De ahí que la visión psicoanalítica no sea considerada como medio para comprender en específico los procesos de fondo generadores de la escritura y la lectura, y de que cuando se estudia a éstas desde el escorzo del psicoanálisis, sea circunscribiéndolas a los procesos conscientes, racionales con lo que quedan comprendidas dentro de una psicología del yo exclusivamente. La lectura como objeto de conocimiento de la Psicología se sustenta así en una concepción racionalista de la misma, parafraseando a Freud, "esta identificación nos parece tan natural que creemos hallar un absurdo manifiesto en todo aquello que la contradiga”. Cabe acotar que esta identificación entre lectura y racionalidad fundamenta la concepción de la información sobre la que se asienta la concepción bibliotecaria; pero la generación de información y la información per se está recorrida por las fuerzas del inconsciente. Para una concepción psicológica que sólo considera a la lectura como un proceso consciente, racional, no caben o, más exactamente, no son dignas de considerarse las equivocaciones en la lectura de las que habla Freud; en última instancia serán consideradas como simples faltas de concentración lectora. Con lo que finalmente es desgajada la lectura de la corporeidad del lector, y se la convierte en esa operación abstracta impugnada por Roger Chartier. 
Una vez vistas someramente las relaciones y propiedades que se dan entre los escorzos social y psicológico de la lectura, veamos ahora sus relaciones con la Historia. Lo que a su vez nos permitirá dar un paso más en profundidad siguiendo la senda del psicoanálisis, y con ello explicar la dimensión inconsciente de la lectura, recuperando con ello el cuerpo lector.

Freud explicaba que una diferencia fundamental y definitoria de las características del ello y del yo era la que radicaba en el tiempo: mientras que en el ello el tiempo no existe, para el yo es su hábitat propio. Por estar dirigida hacia el mundo material la conciencia está a merced de todos los avatares del tiempo que crean y destruyen ese mundo. De hecho el yo se gesta en el tiempo, desde el momento en que se diferencia del ello, y se transforma a su paso, desdoblándose para dar lugar al superyó. Y es este último el que mejor registra el discurrir del tiempo social, porque en él se reflejan los sucesivos cambios de la normatividad de las sociedades. Ese tiempo constitutivo del yo visto desde la amplia perspectiva del discurrir social es la historia, lo que implica la transición del yo individual al yo colectivo y viceversa en el desenvolvimiento de la historia.

A lo largo de la historia el yo se transfigura, asumiendo los cambios específicos y determinantes de las sociedades. Cambios que, como en el caso del nacimiento de las sociedades textuales, quedaron en el superyó, pero además generaron transformaciones en el propio yo. Paralelamente a la historia exterior en la "historia psíquica" del individuo el superyó tiene su origen en el momento que el yo introyecta a la primera figura de autoridad y poder, que Freud consideró era el padre, y a esa primera figura se van adicionando las sucesivas figuras que ejercen poder sobre el individuo a lo largo de su vida. Con lo que el superyó viene a ser también un sistema psíquico en el que se manifiestan, a través de todas esas figuras introyectadas, los valores morales, religiosos, educativos, etcétera, los poderes con que la colectividad se regula a sí misma y mantiene el control sobre cada individuo.

La lectura se constituye como un principio de autoridad que reviste a las figuras introyectadas conformadoras del superyó; esta manera de revestimiento sólo pudo darse con el nacimiento de las sociedades textuales. Desde su origen en esta clase de sociedades la escritura fue tomando un papel preponderante hasta constituirse en un poder omnipotente; detentado primeramente por una casta sacerdotal que dominaba la magia de la escritura y la lectura, con las que además investía a los textos de un carácter sagrado. Los sacerdotes como representantes de la religión de Estado son introyectados para fortalecer al superyó colectivo, son figuras de autoridad y a la vez detentadores de la autoridad de la escritura, lo que históricamente marca una transformación del yo. Conforme la escritura y la lectura pasan a ser prácticas llevadas a cabo por 
un mayor número de personas, dejan esas prácticas de identificarse con una casta de poder, pero en sí mismas son dotadas de un poder propio que por consiguiente dan solidez y fuerza a las figuras introyectadas configuradoras del superyó, y a través de las coerciones que le dictan al yo se dejan escuchar las lecturas, de ahí la autoridad con que llegan a ser investidos ciertos textos y autores. Todo esto se encuentra, por supuesto, en consonancia con la consolidación de las sociedades textuales. Una vez que estas sociedades han quedado claramente establecidas y definidas, por un lado, el yo es estatuido como entidad racional que produce la escritura y la lectura que la descifra, y por el otro, la lectura reviste de mayor solidez y poder al superyó, el cual es utilizado sobre el yo para controlarlo. Y una forma de control es exigirle mayor racionalidad, para que éste reprima con "mayor eficacia" al ello con la mediación del principio de realidad permeado a su vez de la textualidad social. Con esto se cierra el círculo entre una realidad exterior marcada por la textualidad y la instancia psíquica del yo constituida como racionalidad tendiente a la creación de la textualidad por medio de la escritura y la lectura. De hecho en este círculo están unificados aquellos que Paul Ricoeur distinguía como el "mundo del texto" y el "mundo del lector". Así, una vez cerrado el círculo pueden proliferarse los dispositivos de control sobre los lectores, del yo, a través del libro mismo que vehiculiza los textos.

Conforme la producción de libros, fomentada por una sociedad textual bien definida en sus mecanismos de dominación por mediación de la escritura y la lectura, se hace más sofisticada en ellos, se implementan de mejor forma el orden deseado por la autoridad y que pasará a integrarse al superyó con la lectura. Chartier lúcidamente ha expuesto esa mecánica de la dominación que se ha dado en la historia a través de los libros:

El libro apunta siempre a instaurar un orden, sea el de su desciframiento, en el cual debe ser comprendido, sea el orden deseado por la autoridad que lo ha mandado ejecutar o que lo ha permitido. No obstante, este orden, en sus múltiples figuras no es omnipotente para anular la libertad de los lectores. Aun cercenada por las competencias y convenciones, esta libertad sabe cómo tomar atajos y reformular las significaciones que deberían reducirla. Esta dialéctica entre la coerción y la apropiación, entre las imposiciones transgredidas y las libertades refrenadas, no es la misma en todas partes, siempre y para todos. Reconocer sus diversas modalidades, sus variaciones múltiples, constituye el objeto primero de un proyecto de historia de la lectura que se comprometen a captar en sus diferencias las comunidades de lectores y su arte de leer. ${ }^{23}$ 
De este sustancioso texto de Chartier retengamos la idea de "la libertad de los lectores", la cual aquí consideraremos como producto de su encabalgamiento en el principio del placer, y asimismo tengamos en consideración la "dialéctica entre la coerción y la apropiación, entre las imposiciones transgredidas y las libertades refrenadas", que desde el punto de vista de mi argumentación consideraré como una muestra y reflejo de las contradicciones que se presentan entre el principio del placer y el principio de la realidad en torno a la lectura, como se verá más adelante. Al círculo al que se hacía referencia palabras arriba y que contiene los mundos del texto y del lector, lo hace girar la fuerza motriz de una racionalidad dominadora, que deja marginado de todo ese proceso al ello, y con él a la corporeidad.

El ello vive inmerso en su propio ámbito psíquico, el inconsciente, donde la racionalidad se difumina ante la inexistencia de las contradicciones que en él son consustanciales. Y el tiempo sólo es un lejano rumor, por eso en el ello la historia no tiene cabida. Por estas distinciones tan claras parece natural el antagonismo entre el ello y el yo, y por lo mismo parecen consecuentes las posiciones del Yo y el superyó en no permitir que el ello tenga manifestación en la realidad, en sentido específico, de la sociedad textual. Más si el yo y el superyó hacen uso de la represión contra el ello es porque éste no deja de pugnar por exteriorizar sus pulsiones, de buscar satisfacer sus deseos en el mundo exterior. Esta pugna entre represión y satisfacción de las pulsiones, comprendida dentro del marco de la argumentación aquí seguida, puede expresarse como la palabra racionalizada y coaccionadora del yo que busca impedir expresarse a la voz del yo.

Dentro de esta inacabable proliferación de herederos y seguidores de Freud, muy probablemente fue Lacan quien mejor comprendió y desarrolló las intuiciones que aquél tuvo sobre la preponderancia que tiene el lenguaje dentro del aparato psíquico. Lacan de hecho hizo del problema del lenguaje en la psique el eje de su propuesta psicoanalítica, por lo mismo entendió con claridad todas las implicaciones de la "mordaza puesta sobre la palabra" ${ }^{24} \mathrm{del}$ inconsciente que busca dejarse escuchar, de allí los lapsus, los actos fallidos. Palabra amordazada que debe ser liberada, lo que redunda en la liberación lectora.

Las pulsiones buscan satisfacción por medio del principio del placer, por lo que el inconsciente se dirige hacia aquellos objetos que satisfarán sus deseos.

24 "Esta claro, dice Lacan, que todo acto fallido es un discurso logrado, el lapsus se produce por una mordaza puesta sobre la palabra, exactamente con el fin de que 'un buen entendedor entienda' tampoco ocurre así en la elección aparentemente libre de un nombre y en los numerosos índices de un supuesto "azar". El síntoma mismo, producto de conflictos, se resuelve por completo en un análisis de lenguaje, ya que está estructurado como lenguaje, cuya palabra debe ser 'liberada' por el psicoanálisis”. Hesnard, A., op. cit., p. 231. 
Estas pulsiones están a su vez motivadas por la energía libidinal, eros, por consiguiente es energía cargada de vitalidad, lo que implícitamente significa imaginación y creatividad: fuerzas transgresoras y transfiguradoras de lo establecido que propician nuevas formas de organización y convivencia humanas signadas precisamente por la imaginación y la creatividad. Por lo mismo las pulsiones impulsadas por la energía libidinal conllevan un potencial comunicativo que une más humanamente a los individuos. Mas, por otra parte, del inconsciente también emergen pulsiones antagónicas a las anteriores, son aquellas que Freud denomina como instinto de muerte, tánatos; son pulsiones generadoras de violencia que buscan destruir los objetos hacia los que se tiende, cumpliendo así con su designio, regresar la vida hacia lo inorgánico. Las pulsiones son contenidas por las instancias superiores del aparato psíquico, las cuales a su vez en gran medida responden a las disposiciones de control del orden social histórico para llevar a cabo la represión de las pulsiones. Como vimos con anterioridad, en las sociedades textuales las disposiciones de control se plasman y canalizan a través de la escritura y la lectura. Las que al ser interiorizadas como mecanismos de poder que revisten al superyó, se convierten en mandato que ejerce sobre la dimensión racional, configurada como textualidad del yo; el cual, por medio del principio de realidad, reprime las pulsiones libidinales que contienen las fuerzas de la imaginación y la creatividad, que buscan externar su palabra. Palabra enfrentada a la palabra en la arena del aparato psíquico. Es la palabra individual del placer dentro de un orden de textualidad psíquica.

Y este proceso de coerción textualizada se lleva a cabo hasta las mismas fronteras del inconsciente. El preconciente que es el sistema de procesamiento lingüístico entre el inconsciente y el consciente se reconstituye a partir de las disposiciones lingüísticas que le dicta el yo, de ahí que las representaciones del inconsciente que transitan a través de él quedan sometidas a los códigos de textualidad que determina y determinan a la sociedad textual, con lo que las pulsiones, al quedar revestidas lingüísticamente de esa forma, reprimen su carga imaginativa y creativa. Lo que redunda en que el cuerpo que es territorio natural y propio donde se despliegan los instintos no sea partícipe de la lectura. Con lo que las pulsiones se convierten no en transgresoras sino en reproductoras de los códigos de la sociedad textual; pero con eso se deja mayor libertad para manifestarse a las pulsiones de muerte, como lo columbró el propio Freud en sus obras más especulativas y visionarias como Más allá del principio del placer y El malestar en la cultura.

Veamos ahora todo esto en la dimensión inmediata y concreta de la lectura. Dentro de una sociedad textual el lector tiene a su disposición un universo de libros, en su forma orgánica e institucionalizada, contenido en las 
bibliotecas, que están perfectamente codificadas y regimentadas por una serie de dispositivos de control de la materialidad del libro y del texto en el contenido. Dispositivos constituidos a lo largo de la historia a todo lo ancho del sistema de producción de libros y que varían o cambian según las distintas fases por las que pasan históricamente las sociedades textuales. ${ }^{25}$ Cuando el lector abre un libro hay una consonancia de textualidad entre uno y otro. El yo del lector se encuentra articulado por una racionalidad preparada potencialmente (en gran medida por la educación sustentada en la textualidad) para escribir y leer, lo que se corresponde con el texto contenido en el libro. Al leer el texto el lector se ciñe a los dispositivos que organizan ese texto y así lo ofrecen a su lectura. Dispositivos que además nimban de autoridad el libro, con lo que es de esa manera introyectado por el superyó, donde acaba constituyéndose en una instancia de poder. Así ciertas obras y autores en particular son introyectados convirtiéndose en figuras de autoridad constitutivas del superyó; pero el prestigio del acto mismo de leer deviene en esa dimensión del superyó en el famoso saber es poder, todo lo contrario al saber es placer.

El principio de realidad se convierte en instrumento que legitima esa forma de leer y sanciona las desviaciones. Las lecturas que están en consonancia con la realidad textual o, más exactamente, de la sociedad textual son legitimadas y fomentadas para continuarse así, de donde surge el perfil del lector dócil. Esta forma de leer reconstituye la organicidad lingüística del preconciente, con lo que se pone cerrojo a la pulsión libidinal, o, al menos, eso es lo que toda esa parafernalia psíquica coercitiva pretende.

No todos los lectores son dóciles e incluso los que tenazmente lo son, suelen tener aunque sea fugaces parpadeos de desviacionismo de la norma lectora. Esquirlas, zonas recónditas y segmentos imprevisibles del texto leído escapan a la lectura controlada del yo y, perforando los distintos puestos aduanales de represión, se incrustan en el inconsciente, donde como excitaciones venidas del exterior despiertan deseos que pugnan por satisfacción. El principio del placer busca la satisfacción del ello en esa otra parte del texto a través de una lectura transgresora: imaginativa y creativa; esto es, lectura como placer. Lectura que conduce al saber como placer. Lectura que manifiesta la libertad del lector. Que incluso transgrede los dispositivos de control sobre los que está montado el texto. Ahora bien, los objetos exteriores con los que busca satisfacción el

25 Para una más amplia y detallada explicación sobre la problemática de los dispositivos de control y dirección de la lectura, a partir de la historia de los sistemas de producción bibliográfica en las sociedades textuales europeas, véanse los libros de Roger Chartier (aparte del ya citado): Libros, lecturas y lectores en la Edad Moderna, Madrid, Alianza, 1993; Culture écrite et societé, París, Albin Michel, 1996. 
principio del placer no necesariamente sólo son objetos materiales, pueden ser también objetos simbólicos como los que ofrece un texto. El procesamiento inconsciente de esos objetos simbólicos se denota, por ejemplo, en los sueños. Freud indica que los libros leídos contribuyen a la elaboración de los sueños, tanto en su textura lingüística como en su trama narrativa.

El desviacionismo del lector es de inmediato reprimido, y genera el sentimiento de culpa que tiene su fundamento en ese precepto social de que la verdadera y auténtica lectura es para conocer, no para engolfarse en el placer. Detrás de ese sentimiento de culpa por incurrir en la lectura como placer, se extiende la sombra del superyó. A los lectores que perseveran en el vicio de la lectura de placer se les arrincona en el ghetto de las lecturas de "ficción". Lo que de ninguna manera puede admitirse es que los "textos serios" de las auténticas disciplinas de conocimiento sean leídos con y por placer. Pueden ser leídos como una necesidad (con vistas a un aprovechamiento profesional o social) e incluso como una obligación, pero jamás como un placer, eso es un verdadero despropósito. Leer, por ejemplo, la obra de Freud como una lectura de placer ¡imposible! Cuando él hubiera sentido placer de que lo leyeran con placer. Es de acotarse que el conjunto de la obra escrita freudiana reúne los atributos apropiados para una lectura con todo derecho placentera. ${ }^{26}$

Es en el conflicto descrito entre el principio del placer y el principio de la realidad donde igualmente puede ubicarse la dialéctica de la que habla Chartier "entre la coerción y la apropiación, entre las imposiciones transgredidas y las libertades refrenadas" en la lectura; que no sólo es una dialéctica que se desenvuelve en la dimensión histórica sino también en la psique, al grado de que puede hablarse de una relación recursiva entre las dos dimensiones. Mas en la medida que el principio de realidad tiende a prevalecer en la lectura, "la coerción" y las "libertades refrenadas" se convierten en valladar contra el principio del placer. Lo que asimismo redunda en que el instinto de muerte no sea contrabalanceado con la fuerza debida por el instinto de vida:

$26 \mathrm{Al}$ contrario de las lecturas de placer (elaboradas bajo esa orientación y leídas como tales), las lecturas serias que se pretenden de conocimiento, son elaboradas de tal forma que, respondiendo a los requerimientos sociales de lo que se espera de ellas, son escritas de tal forma que cierran los resquicios que pudieran dar lugar a una lectura de placer, con lo que queda solidificada la barrera que distancia a ambos tipos de lecturas y de actitudes lectoras ante ellas. A la base de tales antítesis hay un falso problema: se cree que una lectura de placer no puede generar conocimiento en sentido estricto de la palabra, mientras que ésa es la finalidad de las lecturas "serias", empero, esto no siempre es así de simple. Una lectura de placer puede conducir directamente al saber, esto es a la sabiduría para vivir. Sabiduría y conocimiento no son lo mismo, pero se relacionan estrechamente. Así, el conocimiento (el conocer) puede conducir a la sabiduría (el saber), dándole a ésta una firme base cognoscitiva para mejor vivir la vida. La sabiduría puede aportarle al conocimiento una base más humana para que pueda desarrollarse y no se hunda en el abstraccionismo. Y una lectura seria cuya misión es generar conocimiento en no pocas veces acaba obnubilando ese mismo conocimiento. 
El Yo no se conduce imparcialmente con respecto a las dos clases de instintos. Mediante su labor de identificación y sublimación auxilia a los instintos de muerte del Ello en el sojuzgamiento de la libido, pero al obrar así se expone al peligro de ser tomado como objeto de tales instintos y sucumbir víctima de ellos. ${ }^{27}$

Por otra parte, es en este conflicto entre el yo y el ello en la dimensión lingüística que gira en torno a la lectura, donde surgen los actos fallidos, equivocaciones que se dan en ella. Los lapsus que se presentan en la lectura tienen una especificidad y diferencia respecto a los demás señalados por Freud, como por ejemplo romper y olvidar objetos, caerse, etcétera, la cual radica en su carácter lingüístico. Y aunque si bien todos los actos fallidos tienen en común ser la respuesta a una represión que sufren los deseos que proyecta el inconsciente, en el caso a los referentes a la lectura esa respuesta tiene un contenido particular producto de la dinámica del lenguaje textual con que se recubre. Un deseo busca externarse pero por el displacer que puede acarrear o porque puede contravenir el orden moral imperante es reprimido, por lo que busca otros canales para externarse y producir así un acto fallido. Freud dando mayor precisión explicativa al desenvolvimiento del proceso que conduce a los actos fallidos explica:

... que los actos fallidos resultan de la interferencia de las intenciones diferentes, una de las cuales puede calificarse de perturbada, y la otra, de perturbadora. Las intenciones perturbadas no plantean ningún problema. En cambio, por lo que respecta a las perturbadoras, quisiéramos saber de qué género son tales intenciones, capaces de perturbar otras, y cuál es la relación que con estas últimas las enlaza. ${ }^{28}$

En el caso de la lectura hay una intención en la que el lector se dirige al texto para leerlo y comprender su contenido, ésta es la intención perturbada porque no logra llevar a cabo ese cometido plenamente. La intención perturbadora es la que con su acción induce a que una intención no se realice de la manera normal perturbándola. La intención perturbadora se encuentra interfiriendo a la intención perturbada y esto desemboca en la transacción del acto fallido, ${ }^{29}$ que en la lectura es de dos tipos: a) cuando se transforma

27 Freud, S., El 'Yo' y el 'Ello', ed.cit., p. 1233.

28 Freud, S., Introducción al psicoanálisis, ed. cit., pp. 87-88.

29 "Sabemos no sólo que son actos psíquicos poseedores de un sentido y una intención y resultantes de la interferencia de dos intenciones diferentes, sino también que una de estas intenciones tiene que haber sufrido antes del discurso una cierta represión para poder manifestarse por la perturbación de otra. Antes de llegar a ser perturbadora tiene que haber sido a su vez perturbada (...) Pero las funciones fallidas son resultado de transacciones en las que cada una de las dos intenciones se impone en parte y en parte fracasa, resultando así que la intención amenazada no queda suprimida por completo, pero tampoco logra -salvo en casos aislados-manifestarse sin modificación alguna”. Ibidem. 
el texto (una palabra se cambia por otra) "porque se lee algo relativo a los pensamientos que en ese momento ocupan al lector"; b) cuando el contenido del texto "provoca una resistencia porque contiene algo doloroso" o, por el contrario, "provoca una realización de deseos". En el caso de la lectura, por lo que se ha explicado anteriormente, ambas intenciones tienen una relación de contenido que los enlaza: la textualidad; porque una y otra se integran de manera lingüística, pero una conformación lingüística signada por la misma normatividad que configura a la sociedad textual. La intención perturbadora haciendo uso de palabras perturba la intención de leer palabras, sea cambiando unas por otras o provocando resistencia hacia el texto leído. Esto en cuanto a la relación que enlaza a una y otra intención, pero falta saber de qué género son tales intenciones.

Tanto el uno como el otro grupo de equivocaciones que se presentan en la lectura son producto de tendencias que se encuentran reprimidas; pero es el tipo de represión y su movimiento interno el que diferencia y desemboca en cada grupo de equivocaciones, y téngase presente que esto lo estamos comprendiendo desde el ángulo de la textualidad que reviste a la tendencia reprimida, ${ }^{30}$ el lector cambia palabras del texto por palabras que en ese momento cruzan su pensamiento, palabras que se encuentran dentro del fluir mental que corre paralelo a la lectura. Esas palabras portadoras de una fuerte carga de energía y sentido, son una especie de anclaje que ese flujo mental lanza sobre el texto para poseerlo transformándolo. En ese flujo mental del lector que lleva a cabo su lectura se da la pugna entre el principio de realidad y el principio del placer. Por un lado la exigencia de leer el texto de acuerdo con el desideratum de conciencia y racionalidad que exige el código de la sociedad textual de cómo debe leerse correctamente; por otro lado, el deseo de transgredir esa forma conciente de lectura para apropiársela de manera gozosa. Y de esa pugna en el interior del flujo mental se desgajan palabras con una fuerte carga de energía libidinal que buscan un sentido placentero al incrustarse en el texto leído transfigurando la palabra sobre la que recae su anclaje, buscando transformar así el texto a la medida de la satisfacción de su deseo. Pero el texto se conserva inmutable ante ese vano intento y lo único que queda es el efímero parpadeo del acto fallido. De hecho la existencia misma del acto fallido es muestra de ese fracaso: la búsqueda de placer en la lectura ha sido acallada; pero la puerta ha quedado abierta.

30 Repito, lo que no significa que esté negando la otra dimensión de la tendencia reprimida, la que obedece a aquella parte de instintos egoístas, de envidia, de odio, etcétera, que son reprimidos. Lo que hago es resaltar su revestimiento lingüístico (textual) que conlleva impulsos libidinales que buscan ser satisfechos con la apropiación del objeto hacia el que se dirige en este caso el texto. 
El otro grupo de equivocaciones entraña un grado mayor de complejidad. En ellas el texto es el que genera la resistencia por su contenido doloroso, pero también incita a la realización de deseos. Veamos primero esta dimensión dual del texto. A semejanza de la lectura, en la escritura se encuentran en pugna los principios del placer y de realidad. El autor de un texto proyecta en su escritura ambas dimensiones: por un lado el impulso creador que emerge de su inconsciente y que se encuentra tensionado por el placer y, por el otro lado, los procesos concientes, racionalizadores del yo, que organizan la escritura a partir de códigos gramaticales, sintácticos, semánticos, etcétera, pero asimismo esta organización de la escritura sufre otra restricción, la que impone su adaptación a un texto que estará contenido en un libro. La escritura destinada a ser publicada en libro (o cualquier soporte impreso) es modificada por los dispositivos de control, que impone todo el sistema de publicación y que dictan con eso, incluso, la forma en que ha de ser leído el texto. La disposición tipográfica acaba por oponerle una firme contención para que no se desborde la pulsión placentera con que el autor concibió su texto o, en todo caso, la pulsión guiada por el principio del placer queda desfigurada al pasar por todas esas instancias racionalizadoras hasta quedar irreconocible su deseo original. Pero incluso el propio autor se impone conscientemente esa limitación al darle privilegiamiento racional ( en aras también a la expectativa de publicación) a la elaboración de su escritura; esto es, que el superyó sanciona al yo en el mismo momento de la escritura, lo que a su vez está en consonancia con los códigos de textualidad que organizan a la propia sociedad textual. De esta forma, en el libro que se ofrece a la lectura, la pulsión en él contenida (en el doble sentido de la palabra) se amortigua entre los dispositivos controladores de tinta y racionalidad.

El lector al abrir un libro con lo primero que se encuentra es con estos dispositivos de control del texto establecidos por políticas de edición y que ejercen la primera forma de determinación sobre su lectura. Conforme avanza en la lectura el lector se enfrenta a los mecanismos de control de la escritura misma y por último a las censuras racionalizadoras del propio autor en el contenido de su texto y en su impulso imaginativo creador. Así, la lectura se despliega a través de tales dispositivos que van determinando la manera inmediata en la que ha de ser leído el texto. El yo del lector se ciñe al seguimiento de tales dispositivos para comprender el contenido inmediato y racional del texto, pero como se explicó líneas atrás, en ese fluir mental que va siguiendo al texto también se despliega el inconsciente, por lo que en el acto mismo de lectura se confrontan el principio de realidad y el principio del placer. Mientras la dimensión consciente del lector queda mediatizada por los dispositivos de control del texto, la dimensión inconsciente traspasa 
tales dispositivos para proyectarse en la zona profunda del texto; en esa zona que el propio autor no pudo evitar plasmar en su texto. Por lo que podría decirse que se establece una vía de comunicación, transferencia, entre el inconsciente del autor y el inconsciente del lector, de lo cual naturalmente no son conscientes ninguno de los dos. Con lo que se ubican en la esfera donde interacciona el inconsciente colectivo.

El autor construye objetos simbólicos por medio de la escritura en los cuales plasma los procesos de su inconsciente, con su propia problemática, pero también lo que ha captado su consciente e inconsciente de todo aquello que ha vivido y leído. De ahí la honda riqueza de los objetos simbólicos que ofrece el corazón de sus textos. Hacia tales objetos simbólicos se tiende subterráneamente el principio del placer del lector. Son esos objetos simbólicos los que, como señala Freud, actúan sobre el lector provocando una resistencia contra el texto porque contiene algo doloroso o provoca una realización de deseos: lo que finalmente redunda en equivocaciones en la lectura. Pero, ¿por qué el matiz distintivo entre la provocación de dolor y la realización de deseos? De hecho el propio Freud diría que son las dos caras de la moneda. Puede ser doloroso porque el autor plasmó algo que pudiendo haber sido doloroso también para él, es así captado por el inconsciente del lector; o, que siendo algo placentero para el autor al pasar por todas las mediaciones racionalizadoras del texto acabó por ser distorsionado hasta convertirse en algo distinto, en algo doloroso. En cuanto a la realización de deseos, no sólo debe entenderse como algo satisfactorio y, por ende, placentero; como todo en la obra de Freud, las cosas no son como parecen. Satisfacer un deseo implica también algo doloroso. La pulsión libidinal (e incluso la de muerte) busca la satisfacción, y, por consiguiente, el placer que eso acarrea, en la posesión del objeto deseado; esa satisfacción puede estar nimbada por ejemplo de egoísmo con lo que al poseer el objeto deseado se vierte sobre él esa carga de egoísmo generando con ello dolor. Pero asimismo puede darse el movimiento inverso, la satisfacción del deseo puede estar signada por una orientación positiva hacia el objeto simbólico que ofrece el texto, pero al de llegar a él cruzando las mediaciones de los dispositivos de control de la textualidad acaba por difuminar esa orientación positiva, con lo que la satisfacción del deseo no alcanza a ser placentera, de ahí finalmente la resistencia del lector frente al texto y las equivocaciones que a cada paso obstruyen su lectura. Pero en una u otra situación lo que queda de manifiesto es que ese texto que provoca resistencia lo hace porque contiene objetos simbólicos que a ese lector en particular le afectan, mientras que a otros les puede ser indiferente. Es lugar común entre los lectores decir que cuando dejaron un libro sin terminar de leer es porque no se conectaron con él, o porque no lo entendieron o porque en ese momento en 
su vida no era el apropiado para ellos. Esto sin considerar que las cualidades per se del libro sean de cuestionable calidad que ameriten su justo (y hasta aconsejable) abandono. Lo cierto es que detrás de tales argumentos pueden preexistir las resistencias inconscientes de las que se ha hablado. 